\title{
ETNOGRAFÍA DE LA NOSTALGIA: MIGRACIÓN TRANSNACIONAL DE COMUNIDADES CHILOTAS EN PUNTA ARENAS (CHILE) Y RÍO GALLEGOS (ARGENTINA) ${ }^{1}$
}

\author{
ETHNOGRAPHY OF NOSTALGIA: TRANSNATIONAL MIGRATION OF \\ CHILOTE COMMUNITIES IN PUNTA ARENAS (CHILE) AND RÍO GALLEGOS \\ (ARGENTINA)
}

\author{
Juan Manuel Saldívar Arellano ${ }^{1}$
}

\begin{abstract}
El artículo se enfoca en mostrar hallazgos etnográficos de la nostalgia manifestada desde la migración vivida entre comunidades transnacionales chilotas ensambladas en Punta Arenas, (Chile) y Río Gallegos (Argentina). Describe la incorporación de elementos culturales vinculados a la formación de comunidades, circulación de mercancías y extensión de significados entre lugares de origen y residencia. Hace énfasis en la representación de la música popular de Chiloé como categoría de análisis e interpretación de experiencias migratorias y ensamblajes multisituados. Esto permite la reflexión de metodologías en movimiento y localización de contextos interactuados multigeográficos.
\end{abstract}

Palabras claves: migración vivida, transnacionalización, nostalgia, música, Chiloé-Río Gallegos.

The article centers around ethnographic findings of nostalgia from the lived migration between Chilote transnational communities assembled in Punta Arenas (Chile) and Río Gallegos, Argentina. It describes the incorporation of cultural elements linked to the formation of communities, goods circulation, and meanings extension between places of origin and destination. It emphasizes the representation of popular music in Chiloé as a category of analysis and interpretation to understand migratory experiences and multi-centered assemblages. This allows the reflection of methodologies in movement (multilocal ethnography) and localization of multigeographic interacted contexts.

Key words: Lived migration, transnationalization, nostalgia, music, Chiloé-Río Gallegos.

Sé que tengo que partir, más no sé si volveré, se que trasteé la frontera en tierra extranjera extraño seré, se que trasteé la frontera de tierra extranjera extraño seré. Lejos mi tierra, mi amada y mi hogar, quiero encontrar en crisol que funda en canción mi ansia de llorar. Antes mi abuelo partió, luego mi padre hizo adiós, y yo quedé tras sus huellas, siguiendo mí estrella errante cantor, y yo quedé tras sus huellas, siguiendo mi estrella de errante cantor. Mi destino es regresar, mi alma ya quiere volar, dormir en su suelo amado, mi cuerpo cansado, su sueño final. Volveré, volveré (Héctor Leiva comunicación personal 2016).

La narrativa corresponde a la canción, Chilote Migrante, entonada por su compositor Héctor Leiva, músico originario de Quellón, Chiloé. Hace referencia a la nostalgia ${ }^{2}$ provocada por el recuerdo de aquellas personas que dejaron el archipiélago para establecerse en diferentes lugares de la Patagonia austral, desde principios del siglo XX hasta la década de 1980 aproximadamente. El auge de estas movilidades, también llamadas migraciones golondrina (Montiel 2010), fueron incentivadas por la búsqueda de trabajo asalariado en la apertura de economías extranjeras principalmente en regiones de Santa Cruz, Magallanes y Tierra del Fuego. Algunos de estos oficios consistían en intensas jornadas laborales relacionadas al cuidado pastoril, pero también en estancias, frigoríficos, zonas petroleras, mineras y otros rubros (Martinic y Campbell 2010). Situar estas movilidades como desplazamientos históricos, implica considerar trayectorias geográficas en diferentes etapas. Durante la década de 1950, el tizón de la papa (Phytophthora

${ }^{1}$ CEDER-Universidad de Los Lagos. Osorno, Chile. juan.saldivar@ulagos.cl 
infestans), provocó desequilibrio en los campos agrícolas del archipiélago, motivando que, aquellos que no habían experimentado la migración, lo hicieran como parte de sus itinerarios laborales buscando solucionar economías de subsistencia (Saliéres et al. 2005). La década de 1960, se presentó como una joroba migratoria provocada por el terremoto que devastó Chiloé (Manns 1972). En la década de 1970, ocurrió el Golpe de Estado, provocando movilidad de chilotes no exiliados hacia Patagonia. Es una etapa importante en la migración que sitúa los ensamblajes $^{3}$ de residencia permanente en lugares de Argentina, es decir, aquellos que cruzaron la frontera no retornaron a Chiloé. A principios de la década de 1980, la apertura de la salmonicultura y decadencia de estancias en Santa Cruz, Magallanes y Tierra del Fuego, cesó considerablemente la migración de chilotes temporeros hacia lugares de Patagonia.

Estudios de la migración en Chile han mostrando interés en diferentes perspectivas científicas, siendo la historia línea de investigación prominente para los escasos trabajos realizados en la macrozona sur patagónica ${ }^{4}$. En el centro del país han concentrado su atención en movilidades históricas y transnacionales, los casos de comunidades peruanas (Garcés 2015; Guizardi y Garcés 2013; Stefoni 2004), cubanas (Saldívar 2015), japonesas (Ferrando 2004), árabes y judías (Agar 2007). Investigaciones recientes localizan movilidades en el Norte Grande derivadas del particularismo económico de expansión en la minería salitrera(González 2009; Valdebenito 2017). De manera que nuevos enfoques analizan también migraciones femeninas en territorios hiperfronterizos adyacentes al Perú y Bolivia (Garcés et al. 2016; Guizardi et al. 2017). Siendo estas investigaciones consideradas como aportes derivados de análisis más amplios que sobreponen antiguas perspectivas de la globalización, versus nuevas referencias sobre transnacionalización. En otros lugares del mundo, se ha estudiado la migración transnacional acentuada en la circulación de tradiciones religiosas originarias, new age y afroamericanas (Argyriadis et al. 2008; Saldívar 2016), extensión de mercados y mercancías (Knauer 2003), maternidades y migración femenina (Pedone y Gil 2008), inclusión étnica (Viladrich y Cook 2008), movilidades laborales (Guarnizo 2003), entre otras.

Este trabajo muestra una reflexión etnográfica en desarrollo sobre la migración transnacional de comunidades chilotas ensambladas en territorios de Punta Arenas, Chile y Río Gallegos, Argentina. Considera dos tipos de sujetos migrantes ${ }^{5}$, retornados al archipiélago y residentes en Patagonia. La unidad de análisis hace referencia a contextos interactuados de Chiloé, Punta Arenas y Río Gallegos, como escenarios de hipermovilidad en la macrozona sur patagónica ${ }^{6}$. Los territorios que los migrantes reconocen como objeto de la nostalgia son lugares de hiperconexión, aquellos en los cuales residieron experimentando la migración laboral. Algunos de los cuestionamientos que se buscan responder son ¿cómo se re-configuraron dimensiones de la nostalgia entre migrantes retornados y residentes que recuerdan experiencias de la vida patagónica? ¿Qué elementos culturales fueron importantes mediadores de conexión transnacional entre Chiloé, Punta Arenas y Río Gallegos? Estudiar la nostalgia como subjetividad implicó conceptualizar circuitos de redes transnacionales como estrategias de organización polisémicas que vinculan tanto "nodos, flujos y enlaces [como también] estructuras, procesos y/o espacios" (Barnes y Reilly 2007:65).

\section{Área de Estudio}

De acuerdo al objetivo central en este trabajo, consideraremos la posición etnográfica desde Chiloé hacia territorios de Punta Arenas y Río Gallegos. En este sentido, el archipiélago se encuentra localizado en el sur de Chile, entre paralelos $41^{\circ}$ y $43^{\circ}$ con una superficie de $9181 \mathrm{~km}^{2}$. Forma parte de la Región deLos Lagos, hasta el último censo de población contaba con 167.659 habitantes (Instituto Nacional de Estadística de Chile 2012). Se encuentra dividido en diez comunas y diferentes islotes administrados políticamente. Las principales ocupaciones son la agricultura (particularmente el cultivo de papa) y la pesca, siendo la pesca artesanal bentónica estrategia económica de subsistencia local desde la década de 1960 hasta la actualidad (Ther Ríos 2011). Después de 1980, se establecen empresas salmonicultoras que propagan el cultivo del salmón en el litoral del mar interior de Chiloé (Saavedra Gallo 2015). Las relaciones históricas entre pesca artesanal y migración son también relevantes para comprender movilidades de chilotes hacia diferentes lugares del sur. Sobre todo algunas poblaciones llamadas pueblos de plástico (Vásquez de Acuña 1993) campamentos y poblados (Silva 2011) en regiones australes de Aysén y Magallanes formadas por asentamientos de pescadores artesanales. La disminución de la migración chilota hacia lugares de Patagonia argentina, se encuentra estrechamente vinculado a la llegada de empresas salmoneras en el archipiélago a principios de la década de los ochenta. Las tradiciones 
culturales se relacionan con mitologías mapuchehulliche (Pandolfi 2016). Son las tradiciones religiosas importantes canales de socialización entre habitantes del archipiélago y el continente, fundamentalmente de carácter judeocristiano, entre ellas el Nazareno de Caguach como referente simbólico (Cárdenas y Trujillo 1986).

La Figura 1 muestra los desplazamientos migratorios de los chilotes hacia el sur austral en dos trayectorias. La Ruta larga, coloreada en azul, navegación desde el archipiélago hacia Magallanes cruzando el golfo de Penas. La ruta corta, coloreada en amarillo, desplazamiento terrestre desde el archipiélago hacia Aysén con dirección a la franja fronteriza sur colindante con el Chubut y los territorios de Santa Cruz y Tierra del Fuego, Argentina.

\section{Materiales y Métodos}

Los avances de investigación mostrados en este trabajo siguieron lineamientos metodológicos del proyecto FONDECYT 3160798. Se desarrollaron diferentes etapas cualitativas de intervención etnográfica ${ }^{7}$ (trabajo de campo) entre diciembre 2015 y mayo 2017, divididas en tres ejes de concentración de información. El primero se refiere a etnografía del viaje. Consistió en una serie de recorridos exploratorios entre el archipiélago de Chiloé (incluyendo islotes como grupo de islas Cailín y Desertores), Punta Arenas y Río Gallegos, desplazamientos terrestres y navegación a bordo del buque "Micalvi" de la Armada de Chile. El segundo consiste en localización de tradiciones culturales unilocales. Esto implicó considerar un primer cuerpo de información a través de la etnografía de los contextos interactuados (ECI), estrategia que permitió encontrarse con el pasado en diferentes ocasiones circunstanciales (revisión de archivo, historias de vida, análisis visual). El tercero es localización de actores y escenarios en contextos multilocales. Se considera la etnografía multisituada (Marcus 1995; Falzon 2009), como referencia para entender conexiones a través del seguimiento circunstancial de personas, objetos, metáforas, tramas, vidas y conflictos en movimiento (entrevistas en profundidad, test psicológicos, encuestas, cartografías). La característica de este trabajo es mostrar lugares geográficos como espacios conceptuales "cuyos significados y límites se negocian de forma continua" (Gallo 2009:89), tipificando complejidades de la migración vivida y sujetos colectivos mediante comparaciones constantes en escenarios multiescalares.

\section{Las subjetividades de la migración transnacional}

La perspectiva transnacional de la migración (Glick-Schiller 2008) es de utilidad al situar no solo procesos de relaciones socioculturales ocurridas más allá de las fronteras nacionales, sino también complejidades vinculadas con desplazamientos y ensamblajes entre lugares de origen y destino. Sobre todo considerando movilidades en lugares sin vínculos geográficos (Goldring y Landolt 2009) donde se manifiestan tradiciones culturales locales (Levitt 1998; Khagram y Levitt 2008). Lo transnacional implica relaciones y conexiones a largas distancias, inmediatez, simultaneidad, participación de redes y circuitos interactuados. La migración transnacional como problema antropológico, considera el análisis de procesos de larga duración y multisituación de escenarios (Marcus 1995). De manera que es de utilidad pensar en una antropología postimperial que desarticule la clasificación entre el yo antropológico y el otro etnográfico (Kearney 2003). Esta etnografía práctica puede también considerarse como una antropología transnacional participativa (Besserer 2016) que involucra comunidades de antiguos y nuevos emigrados referenciados. Dicho enfoque muestra importancia en la localidad de origen de los migrantes, sobre todo pensando en los vínculos generados con lugares de residencia. Es precisamente Glick-Schiller quien propone "(2) evitar las orientaciones próximas al nacionalismo metodológico [y] (3) acercarse a la noción de localidad de un modo relacional" (Glick-Schiller 2008:40). Precisa la necesidad de "recurrir a un enfoque reflexivo que ubique histórica y geográficamente el paradigma de migración transnacional" (Glick-Schiller 2008:29).Así también, desmitificar "el surgimiento de la migración transnacional [atribuido solamente] al desarrollo de nuevas tecnologías [pues] ésta interpretación carece de base histórica" (Glick-Schiller 2008:30). Dichas propuestas han sido repensadas desde un mundo neoliberal y aplicadas a los estudios de migración multilocal que discuten relaciones escalares entre sitios y campos (Sinatti 2008).

De acuerdo a esta discusión, es relevante definir dos conceptos que ayudaran a situar etnografías de la nostalgia. El primero se refiere al ensamblaje global, entendido como formas que "interactúan con otros elementos, ocupando un campo común en contingente $[\ldots]$ no siempre implica nuevas formas, sino formas que están cambiando, en formación o en juego" (Collier y Ong 2005:12). Así también, campo social transnacional, definido como "un conjunto de 

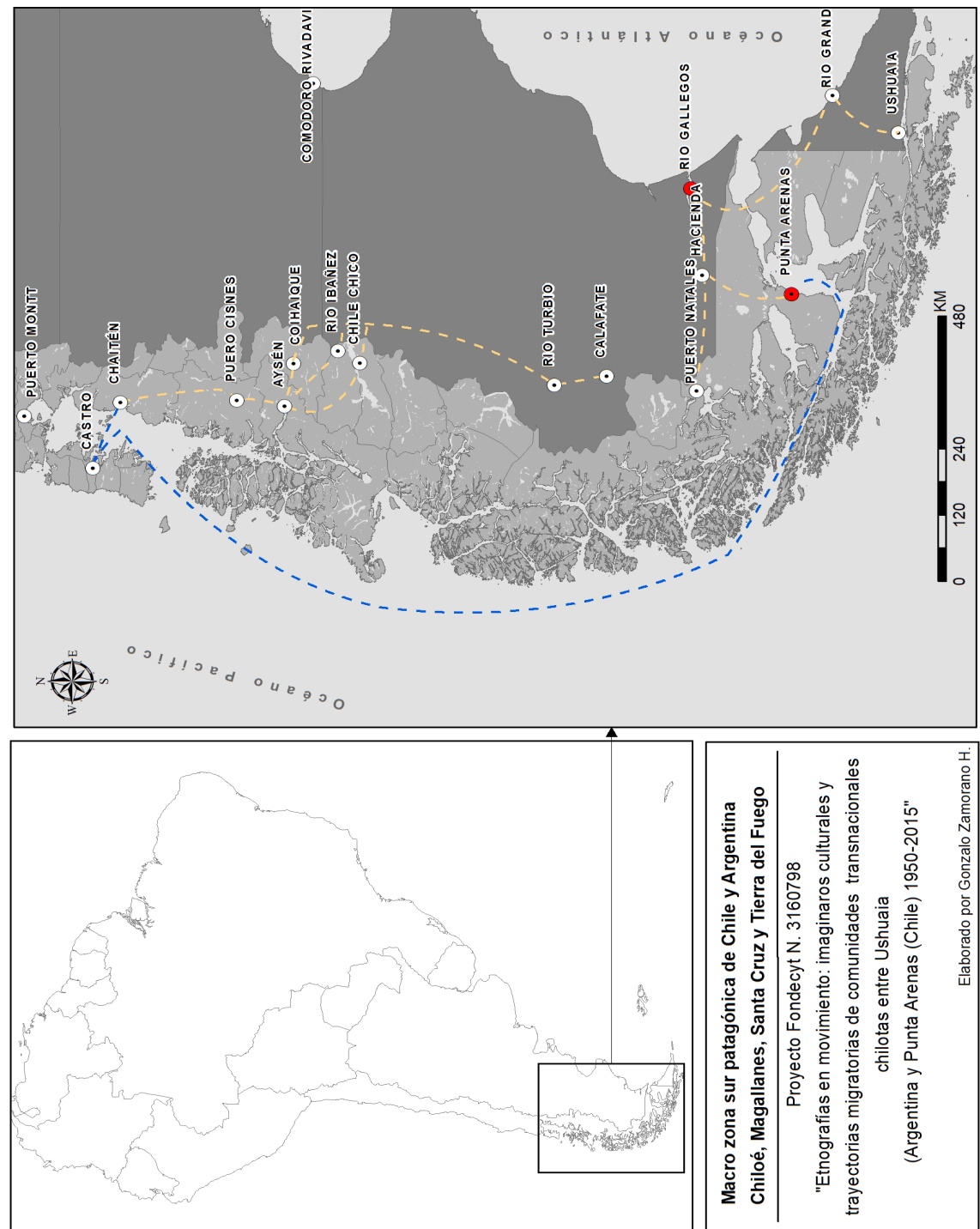

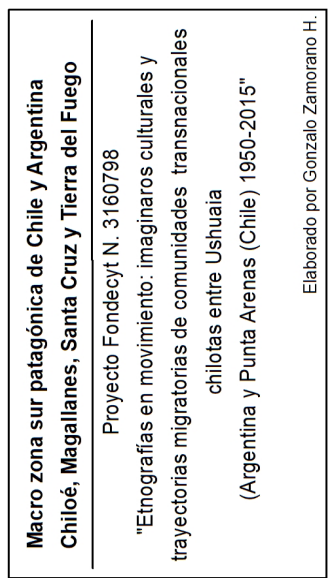


múltiples redes entrelazadas de relaciones sociales, a través de las cuales se intercambian de manera desigual, se organizan y se transforman las ideas, las prácticas y los recursos" (Levitt y Glick-Schiller 2004:66). Estos campos sociales se construyen a través de la vida cotidiana y actividades que los migrantes desarrollan, incluyendo aspectos económicos, políticos y culturales (individuales y grupales). La reflexión se centra en las tradiciones culturales ${ }^{8}$ locales, expresadas desde la matria, la historia compartida, el terruño, la familia y los contextos de interacción. De manera que, son "las comunidades transnacionales [...] pequeños talleres [que dan] por sentado que aquí hay una negociación de significados, valores y formas simbólicas bastante continua [incluyendo] tanto las culturas del lugar anterior como las del nuevo" (Hannerz 1996:161).

\section{Resultados}

\section{Migraciones Patagónicas 1930-1980}

Las migraciones de chilotes hacia Patagonia se originaron por ausencia de oportunidades laborales, "excesiva subdivisión de la tierra, la pobreza general, la inexistencia de industrias y la falta de expectativas en los centros urbanos" (Urbina 2002:361). Un migrante retornado afirma que "entre las décadas de 1930 y 1950 la tradición migratoria hacia el sur era muy fuerte porque en Chiloé no había trabajo y nos teníamos que ir a Patagonia" (Luis Gallardo comunicación personal 2016). También contribuyeron otros factores como el auge de las estancias e inversiones ganaderas que hacían de estos territorios espacios privilegiados. De los cuales "la ovejería generó un desarrollo industrial proyectado en graserías y frigoríficos que exportaban carne y manteca a Europa y al resto del territorio nacional" (Montiel 2010:18). Los principales lugares de asentamiento correspondían al auge laboral, sobre todo la explotación pastoril que incluía esquila y frigorífico en regiones de Santa Cruz y Tierra del Fuego, minería en Río Turbio, petróleo en Comodoro Rivadavia y construcción de casas habitacionales en regiones de Tierra del Fuego. Habría que destacar las rotaciones laborales que hacían los migrantes después de las temporadas entre Argentina y Chile, estas consistían en la "esquila durante meses de diciembre a febrero en Río Gallegos, frigorífico entre marzo y abril en Punta Arenas" (Jesús Yañez comunicación personal 2016). La narrativa hace pensar en los circuitos alternativos de supervivencia que experimentaban comunidades de chilotes entre espacios de circulación laboral que contribuía, también, en desarrollo económico (remesas) para sus lugares de origen.

Estas migraciones golondrinas fueron reservadas mayormente para aquellos que se desenvolvían en las estancias, "se ponían de acuerdo para las comparsas de esquila, viajaban en grupos hacia la Patagonia, empezaban en diciembre y terminaban en enero o marzo contando el frigorífico, entre 3 a 5 meses" (Felipe Montiel comunicación personal 2016). Las comparsas eran integradas por esquiladores, velloneros, prenseros y cocineros, mayormente amigos o familiares directos que mantenían acuerdos con estancieros. El aumento de migrantes procedentes de Chiloé que no regresaban a sus lugares de origen, era incentivado "porque siempre existía la posibilidad de quedarse definitivamente allá, donde además de la esquila, las estancias ofrecían trabajo permanente de ovejero, puestero, amansador de caballos o alambrador" (Urbina 2002:365). Aquellos que lograban asegurar empleos "venían por sus familias a Chiloé, los que eran puesteros iban con su señora e hijos y se quedaban aislados en la pampa, dependían de los víveres que les llevaban cada quince días" (Oscar Soto comunicación personal 2016). Los viajes hacia el sur austral fueron una constante durante décadas de esplendor en las estancias y frigoríficos, minimizando, incluso, el grueso calibre que se desplazó a las salitreras del norte, en Antofagasta o, madereros que circularon entre Apiao, Lemuy y Quellón. Las trayectorias se desarrollaban en buques que partían de Chiloé con destino a Punta Arenas. A propósito, Alicia Paillaleve, folklorista chilote, comparte la canción El Navarino.

Dicen que por el norte ya se viene el Navarino. Dicen que por el norte ya se viene el Navarino, alistá el bastimento para el camino, alistá el bastimento para el camino, para el camino ay sí. Me voy rumbo a Punta Arenas, para el camino ay sí, me voy rumbo a Punta Arenas. Después del Corcovado, Golfo de Penas, después del Corcovado, Golfo de Penas. Golfo de Penas ay sí. El viaje de una semana, golfo de Penas ay sí. El viaje de una semana, sólo jugando al truco pasa las ganas, ya estando en Punta Arenas, allá va, no siento penas (A. Paillaleve comunicación personal 2016).

Durante la década de 1950, el "tizón tardío que arruinó reiteradamente los papales chilotes [...] acarreara una crisis económica y un nuevo impulso a las migraciones patagónicas" (Cárdenas 2004:1). 
Algunos historiadores locales coinciden con el tizón como propulsor de migraciones. Luis Mancilla considera que fueron "momentos difíciles para la economía chilota, el tizón echó a perder todo en la siembra de papa, la gente abandonaba los campos dejaba las casas, se fueron a Patagonia" (L. Mancilla comunicación personal 2016). En la década de 1960, fue el terremoto que ocasionó la "emigración de familias chilotas, campesinos pobres, hacia Patagonia [...] Eran familias completas embarcándose en Castro para la Argentina o Magallanes buscar mejores condiciones de vida" (Mancilla y Mardones 2010:177). La particularidad de la movilidad chilota frente a estos escenarios históricos, es la conexión temprana que mantenían comunidades locales con otras residentes en lugares australes de Patagonia y Tierra del Fuego, particularmente en Punta Arenas y río Gallegos. En la década de 1970, debido al Golpe de Estado, comunidades de chilotes no exiliados se movilizaron hacia Patagonia, "muchas familias chilotas salimos para Argentina buscando mejores condiciones de vida, no queríamos vivir en dictadura" (Josefa Torres comunicación personal 2016). La característica en este tipo de movilidad fue que, "familias enteras se quedaron allá, los que se fueron huyendo por el golpe no regresaron a Chiloé" (María Cárcamo comunicación personal 2016). A principio de la década de 1980 llegaron al Archipiélago diferentes empresas dedicadas al cultivo del salmón (Oncorhynchus), estimulando el efecto salmonera (Saavedra Gallo 2015). Algunos migrantes retornados reconocieron la disminución de la migración" atribuida a las "fuentes de trabajo que ofrecieron las salmoneras en toda la isla y Punta Arenas, cayeron también las estancias en Argentina” (Mario López comunicación personal 2016).

\section{Conexiones transnacionales}

De acuerdo con estos procesos migratorios, tradiciones culturales se ensamblaron en diferentes territorios como parte de las residencias permanentes de chilotes en Patagonia. En el caso de Chiloé se destacan juegos como la taba o el truco, los chilotes eran aficionados a los naipes, estos eran "el pasatiempo en los largos viajes al sur a bordo de vapores" (Urbina 2002:358). Según Felipe Montiel, "los viejos que venían de la Argentina, fueron incorporando la bombacha, la boina, la bota encarrujada, el pañuelo al cuello, estos eran los viejos que venían de la zona gaucha" (F. Montiel comunicación personal 2016). En este sentido, la narrativa de Armando Bahamonde, coincide con Montiel, sosteniendo que "muchos galpones o ranchas en Chiloé están construidos a la usanza argentina, porque los que hicieron eso fueron justamente los que estuvieron allá varios años" (A. Bahamonde comunicación personal 2016). La música fue otro factor de conexión cultural, Sergio Colivoro, músico chilote, asegura que "lo que llamamos acordeón chilota corresponde a un instrumento que llegó en 1930 traído por los mismos chilotes emigrantes que venían de Patagonia argentina" (S. Colivoro comunicación personal 2016). A propósito, en la música de Ramón Yáñez, la canción Somos de Chonchi, muestra este tipo de conexiones.

En el vapor que viaja de Castro a Punta Arenas, se van a la faena pa' allá para Argentina, van los chonchinos, los quelloninos y los cailinos con los achainos. Un marinero pregunta de dónde son, y los de Chonchi responden con glamour, no somos de Tenac, somos de Chonchi, vamos pa' la Argentina, somos de Chonchi, llevamos licor de oro, somos de Chonchi [coro] somos de Chonchi. La ruta que nos guía impronta a los canales para llegar contentos con rumbo a Magallanes, los quenacanos, ancuditanos y los caguachanos, cruzando Golfo de Penas comienzan a gritar y entonces los chonchinos se ponen a cantar ( $R$. Yáñez comunicación personal 2016).

Esta narrativa, a modo de cueca chilota, muestra la migración constante de chilotes hacia territorios de Argentina. Permitiendo la incorporación de tradiciones culturales locales en lugares de residencia migrante. Es Armando Bahamonde quien reconoce cómo "el chilote en su maleta llevaba su cultura a Magallanes y Argentina, eso se quedó allá, ahora notamos lugares como Río Gallegos y otros que lucen tradiciones nuestras" (A. Bahamonde comunicación personal 2016). Las ceremonias mortuorias ${ }^{10}$ por ejemplo, se legitimaron en estos lugares a través de "ceremonias como velar los muertos en casas particulares, tal como se hacía en Chiloé, pagar a un resandero para que haga rezos fúnebres y llevar al difunto en procesión hasta el panteón" (Víctor Téllez comunicación personal 2016). Este tipo de manifestaciones provocaron el arraigo de tradiciones religiosas más amplias, como la veneración del Nazareno de Caguach, legitimado e institucionalizado en Punta Arenas y Río Gallegos. De manera que referencias culturales muestran "las formas en que las personas móviles unifican los símbolos y reconstruyen y representan sus culturas, identidades y nuevas realidades sociales en el contexto transnacional" (Hirai 2012:33). 
Las nociones de espacio vivido (Soja 2008) para los migrantes chilotes, se encuentran asociadas a emociones provocadas por la lejanía, como la nostalgia. Arturo Hueicha, chilote residente en Punta Arenas, nació en Achao y emigró a Magallanes en el año 1979, motivado por las expectativas laborales contadas sobre Patagonia, "mis tíos viajaban todas las temporadas y regresaban cargados de plata" (A. Hueicha comunicación personal 2016). Las expectativas laborales se extendieron durante largos periodos, contribuyendo a que un número considerable de la población no retornara al archipiélago. Arturo Hueicha narra parte de su experiencia:

Llegué a Punta Arenas cuando era cabrito, me fui de alambrador en el campo, la pega [trabajo] era dura pero el hecho de pensar en mi familia se me pasaba el dolor. Así estuve cinco meses sin parar, después me acostumbre. Siempre estuvo fija la idea de regresar a Chiloé con las lucas [dinero] que había ganado y comprar hartos quintales de harina, zapatos para mis hermanos y un campo. Después pensé traerlos a todos. Desde 1980 vivieron conmigo en Punta Arenas, mi madre a los dos años falleció, seguro fue por pena, extrañaba Chiloé. Paso el tiempo y eche de menos mi tierra, acá puede haber trabajo, dinero, lo que sea, pero no es lo mismo. Primero te sientes bien pero después ya no, por ejemplo si tú querí mariscos no puedes ir a mariscar, si querí pescado no puedes ir a pescar. En Chiloé si se puede todo eso, o crear un chancho o una gallina, acá no poh. Yo pienso que los que se trajeron a sus papás y se murieron fue por pena (A. Hueicha comunicación personal 2016).

La manifestación de la nostalgia entre migrantes residentes en Punta Arenas, contribuyó en la creación de lazos afectivos, expansión y extensión de espacios, tales como centros culturales, deportivos, radiodifusoras, mercados, barrios, tradiciones religiosas y otros elementos propios de la migración transnacional. Algunos de estos espacios resaltan la gastronomía chilota, sobre todo aquellos que se han legitimado como lugares de chilotes, restaurantes como Centro Hijos de Chiloé, El Mercado Chilote, Donde Hueicha, entre otros. Además de ofrecer gastronomía, muestran tradiciones musicales que permiten imaginar y vivir el terruño fuera del mismo. Víctor Téllez, recuerda haber conocido comunidades de migrantes que formaban "clubes, centros chilenos de toda la isla, de Queilen, de Compu, de Yaldad, de Castro, de Quemchi” (V. Téllez comunicación personal 2016). Las radiodifusoras también fueron importantes canales de transmisión identitaria. Arturo Hueicha recuerda que "había un locutor, el señor Cárcamo, él siempre dejó en alto a Chiloé, decía en la radio, coman luche, cochallullo, a nosotros los viejos trabajadores de la esquila y pescadores nos hace bien para estar todos firmes [buena salud]" (A. Hueicha comunicación personal 2016). Los mercados populares chilotes, mayormente localizados en casas particulares o tienditas, muestran circulación de ingredientes culinarios llevados por amigos y familiares visitantes desde Chiloé. Hugo Antipani menciona que "cuando uno viaja a Punta Arenas se lleva harina tostada, ajo chilote, cecina, queso, miel, salmón ahumado" (H. Antipani comunicación personal 2016). Elementos básicos de la cocina chilota para elaboración de gastronomías, como chochoca, milcao, chapalele, cazuela, curanto, empanadas de manzana, etc. Este tipo de mercancías se convierten en "objetos de recuerdo y apego cultural de los migrantes $[\ldots]$ a medida que los objetos se transmiten a las generaciones más jóvenes" (Bonnett 2016:98). Los mercados representan conexiones simbólicas que refuerzan identidades, ampliando los imaginarios de la nostalgia para seguir custodiando tradiciones en territorios vividos. Estas aproximaciones culturales son reservadas mayormente en poblaciones como 18 de Septiembre, Pingüino y Prat, donde también tiene lugar la tradición religiosa del Nazareno de Caguach de Punta Arenas y representatividad de estos barrios en una liga local de fútbol.

Siguiendo la discusión, habría que pensar en los espacios vividos como escenarios de la nostalgia, lugares donde se "reconstruye[n] [...] sus fronteras para izarlas hasta las esferas de lo imaginario, del sueño, de la memoria [comprendiendo] las tensiones y conflictos que experimenta el migrante cuando cambia de país" (Sassone 2002:105-106). Si bien es cierto que la nostalgia se refiere a la ausencia de cotidianidades espaciales y temporales (lugares de origen), son justamente aquellos lugares de residencia donde se manifiestan con mayor intensidad elementos de la matria, debido a la creación imaginaria del terruño. Es entonces el territorio un "lugar simultaneamente real e imaginario [...] de experiencias y agencias estructuradas, individuales y colectivas" (Soja 2008:40). El mismo autor reconoce el espacio vivido como tercer espacio, permitiendo la imaginación geográfica del territorio habitado a través de los significados que lo caracterizan, "en su alcance y 
complejidad, con el tiempo vivido" (Soja 1997:75). Cuando nos referimos al espacio vivido de los migrantes chilotes, aludimos a la macrozona sur como territorio que incluye el norte de la patagonia desde Chiloé insular y continental hasta Tierra del Fuego chilena y argentina. Este espacio es definido como un territorio interactuado de conexiones, un espacio cosmopolítico pluriverso que se manifiesta más allá del Estado-nación y, un campo social transnacional que permite circulaciones culturales y tradiciones movedizas.

Según los hallazgos presentados sobre Punta Arenas, del otro lado de la frontera, en Río Gallegos, las prácticas culturales de referencia chilota se manifiestan mediante códigos reterritorializados. Pues los centros culturales, los lugares de ocio, ligas deportivas y tradiciones religiosas, destacan la ampliación de identidades situadas en territorios extranjeros. La Asociación Centro Chileno en Río Gallegos, es un espacio de reunión migrante en el cual se desarrollan eventos culturales tales como Música folklórica, Festival de Cueca Chilena, danzas y alojamiento para migrantes. Cristina Caipillán, chilena residente, directora del centro, recuerda que "antes nos reuníamos los chilenos y hacíamos eventos al estilo chilote, ahora ya son los hijos de chilenos los que procuran el centro, ellos ya son nacidos acá, son argentinos" (C. Caipillán comunicación personal 2016). Tirso Molina, migrante retornado, recuerda el centro como "un lugar grandote donde nos reuníamos los chilenos a celebrar fiestas patrias [18 de septiembre], nos vestíamos de huaso, bailábamos cueca, era como estar en Chiloé" (T. Molina comunicación personal 2016). También se manifiestan preferencias por lugares de ocio, como el RestaurantBar El Canelo, José López, migrante retornado, recuerda "cuando terminábamos temporada nos juntábamos a tomar copete [bebidas alcohólicas] en El Canelo, se hacían los manso carretes [fiestas], era casi como una regla antes de regresar a Chiloé" (J. López comunicación personal 2016). En ligas deportivas de la ciudad se tiene representatividad mediante equipos de barrios chilenos como Evita y Belgrano. Una de las particularidades localizadas entre la comunidad de chilotes en Río Gallegos, es la devoción religiosa a Jesús Nazareno de Río Gallegos. Según la narrativa de Eva Flórez, en la fiesta no pueden faltar "las banderas de Argentina y de Chile, se toca folklor chileno y argentino, cueca y chacarera" (E. Flórez comunicación personal 2016). Don Hilario, chilote residente, menciona que la fiesta es importante porque "al estar en un lugar extraño todos estos migrantes se unieron porque los ligaba la tradición y querían vivir un Chiloé pequeñito en Río Gallegos" (Don Hilario comunicación personal 2016).

Las tradiciones culturales en lugares de residencia migrante, son reflejos que permiten situar aspectos más amplios de los lugares de origen, como "un proceso inacabado de creación-recreación, producciónreproducción, continuidad-discontinuidad; un sistema en constante renovación [... ] vinculada a la categoría tiempo, remite al pasado pero también al presente vivo, porque (la tradición) significa continuidad" (Arévalo 2004:928). En este sentido, la nostalgia se manifiesta como un continuum de lazos afectivos e identitarios más allá de las fronteras. Las relaciones entre individuos y contextos, permiten fluctuación de redes a través de escenarios multiescalares. Estas redes pueden concebirse como "algo que tiene efectos sobre o que se conecta a un nodo [chilotes en Patagonia] un grupo de conexiones y desconexiones [tradiciones culturales] un patrón o cantidad de flujos [matria] una estructura [pensamiento y acción] un tipo de espacio [lugares de residencia] (Barnes y Reilly 2007:66). Las circulaciones de mercancías (objetos, gastronomías) chilotas en Punta Arenas y Río Gallegos se relacionan con lo que autores como Hirai (2012), estudiando migración de mexicanos en California, Estados Unidos, reconoce como mercados de la nostalgia. Hace referencia a una serie de códigos culturales compartidos por comunidades que manifiestan tradiciones en diferentes ámbitos de la vida migrante. Las conexiones que generan los mercados son vínculos afectivos entre lugares de origen y residencia, brindan la posibilidad de "encontrar productos [y] recordar sus terruños [...] y sentir que están en su "casa" (Hiraí 2012:280). Sin embargo, Steigenga et al. estudiando migrantes guatemaltecos en Florida, Estados Unidos, mencionan que "en muchos casos, las reconstrucciones del "hogar" son más imaginadas que reales. La nostalgia [y] las cambiantes identidades transnacionales interrumpen [...] las concepciones del hogar reconstruido" (Steigenga et al. 2008:40).

\section{Discusión}

\section{Nostalgias Patagónicas}

Desde una perspectiva psicopatológica, la nostalgia puede entenderse como duelo migratorio (Achotegui 1999), refiriéndose al transtorno por somatización o distímico, conocido como "Síndrome de Ulises", [...] "Mal del Inmigrante", "Síndrome del Emigrante", "Morriña", "Melancolía", "Nostalgia del Extranjero", "El bajón de los seis meses" (González Calvo 2005:78). De acuerdo con lo anterior, Sigmund 
Freud (1974) reconoció el duelo como la reacción momentánea de afecciones somáticas y, la melancolía, como la pérdida del ideal del yo, estado anímico permanente de desinterés por el exterior. La nostalgia como articulador de relaciones simbólicas, se refiere a "la soledad, la tristeza, el dolor, el sujeto siente el contraste entre el terruño donde vivió antes y el lugar donde se encuentra actualmente, y entre su pasado y su vida presente, y dirige la añoranza hacia [su lugar de origen]" (Hirai 2012:158). Esta idea de nostalgia como extrañamiento, también puede entenderse como sensación de refugio, lugar de encuentro y función de habitar. La concepción de la matria, representa aquel espacio o "mundo pequeño, débil, femenino, sentimental de la madre; es decir, la familia, el terruño, la patria chica" (González y González 1986:15). La memoria de la nostalgia incluye los territorios vividos, tanto de lugares de origen como de residencia, Boym (2016) sostiene que la nostalgia es restaurativa y reflexiva. Aquellos lugares restaurados se legitiman a través de paisajes, en la construcción de monumentos, barrios, espacios de ocio, mercancías y otros elementos que permiten imaginar el terruño.

Los lugares de residencia migrante son hábitats de significado en cuanto provocan ausencias, como la melancolía, misma que "se convierte en una red mediadora que comunica entre sí a seres que sufren e intentan comprender la soledad y el aislamiento" (Bartra 2001:229). Los territorios que los migrantes imaginan como objeto de nostalgia son lugares de conexión, la nostalgia no sólo es un sentimiento que se refiere a la ausencia de relaciones, sino también a la necesidad de recrear los espacios imaginados. En este sentido, "los recuerdos nostálgicos, las reliquias familiares, así como el consumo de bienes nostálgicos, posibilitan, sostienen y responden a la experiencia vivida de la migración" (Bonett 2016:98). De acuerdo a estas consideraciones, cabe destacar la dimensión afectiva ${ }^{11}$ que provoca la nostalgia como parte de un universo simbólico de emociones vinculados con tradiciones musicales, expresadas en melodías, sonetos y tradiciones folklóricas generacionales. Sobre todo porque la música fue un importante canal de transmisión oral, un flux capacitor ${ }^{12}$ que permitió la conservación de la memoria en los territorios vividos. Esto hace referencia a la música como un componente que es adquirido y legitimado a través de experiencias colectivas, sobre todo por "estar al servicio de los momentos culminantes de la vida del hombre, por querer comunicar hechos" (Dannemann 1974:270).

Las conexiones transnacionales manifestadas desde la migración vivida ${ }^{13}$ corresponden a una serie de elementos culturales incorporados en diferentes contextos interactuados ${ }^{14}$ de Chiloé y Patagonia. Situar la nostalgia dentro del campo de las migraciones transnacionales, es de utilidad para reflexionar en las complejidades de la vida migrante. En Chiloé, la ausencia de aquellos que dejaron el archipiélago provocó la extensión de lazos afectivos más allá de las fronteras. En Patagonia, el extrañamiento del terruño estimuló la recreación de espacios mediante el ensamblaje de prácticas y tradiciones. Ambos espacios forman parte de un campo social transnacional que reúne una serie de códigos culturales entrelazados más allá de una geografía particular. Sin embargo, son las tradiciones culturales chilotas las que mayormente se han visibilizado en Patagonia a través de la extensión de mercados, circulación de objetos, creación de espacios de ocio, envío de remesas, tradiciones mortuorias, ligas de fútbol e instituciones que representan sus lugares de origen. Estos migrantes han creado y reforzado una comunidad transnacional transformando identidades colectivas en la creación de espacios como la celebración de fiestas chilotas y no menos las tradiciones religiosas de Jesús Nazareno de Caguach extendidas en Río Gallegos y Punta Arenas. Los vínculos asiduos que han mantenido estas comunidades con sus lugares de origen, han sido canales de conservación de tradiciones culturales expresadas en ritmos y melodías que aluden al extrañamiento de aquellos que dejaron el archipiélago para residir en otros lugares australes.

\section{Conclusiones}

En este trabajo se mostraron hallazgos etnográficos sobre la migración transnacional de comunidades chilotas entre Punta Arenas y Río Gallegos. Estos fenómenos migratorios ocurridos en la macrozona sur patagónica también podrían considerarse como un microtransnacionalismo destacando el universo simbólico del cual forma parte. Las conexiones transnacionales de la nostalgia se representan a través de formación de comunidades, circulación de mercancías y ensamblaje de tradiciones culturales en ambos lados de la frontera. Como resultado de estas movilidades, se han localizado una serie de particularidades referentes a la continuidad de tradiciones entre lugares de origen y residencia migratoria. Ha sido la música un importante canal de transmisión oral y manifestación de experiencias vividas más allá de la matria. Esta conjetura permite comprender procesos ambivalentes de ensamblajes culturales en territorios multiescalares, como sistemas de códigos referenciados pertenecientes a un cuerpo más amplio de imágenes e imaginarios 
reales y simbólicos. De manera que la recreación de los espacios de residencia, permiten la construcción imaginaria de paisajes locales, relacionados con tradiciones culturales de sus lugares de origen. Estas conexiones sitúan Patagonia como un espacio no dislocado, sino como la continuidad histórica y simbólica del territorio, generando una serie de relaciones políticas, económicas y culturales entre personas, países y lugares.

Agradecimientos: Este trabajo muestra avances etnográficos del Proyecto FONDECYT 3160798: "Etnografías en movimiento, imaginarios culturales y trayectorias migratorias de comunidades transnacionales chilotas entre Ushuaia, Argentina y
Punta Arenas, Chile 1950-2015". Los agradecimientos van dirigidos para el Programa ATLAS y CEDER de la Universidad de Los Lagos y la Comisión Nacional de Investigación Científica y Tecnológica (CONICYT). Igualmente a Francisco Ther Ríos, por su entusiasta revisión del manuscrito, Gonzalo Zamorano por la elaboración de mapas de localización y a los evaluadores anónimos de Chungara Revista de Antropología Chilena. Finalmente, destacamos la buena voluntad de los migrantes retornados chilotes y residentes en Patagonia Austral, quienes han tenido la disposición de recibirme y narrarme sus experiencias transnacionales. Cualquier inexactitud contenida en este trabajo es de mi entera responsabilidad.

\section{Referencias Citadas}

Achotegui, J. 1999. Los duelos de la migración: una perspectiva psicopatológica y psicosocial. En Medicina y Cultura, E. Perdiguero y J. Comelles, pp. 88-100. Editorial Bellaterra, Barcelona.

Agar, L. 2007. Árabes y judíos en Chile: apuntes sobre la inmigración y la integración social. En Árabes y Judios en América Latina. Historia, Representaciones y Desafios, compilado por I. Klich y R. Saba, pp. 12-32. Editorial Siglo XXI, Buenos Aires.

Arévalo, J.M. 2004. La tradición, el patrimonio y la identidad. Revista de Estudios Extremeños 60 (3):925-956.

Argyriadis, K., R. De la Torre, C. Gutiérrez y A. Aguilar 2008. Raíces en Movimiento: Prácticas Religiosas Tradicionales en Contextos Translocales. Centro de Estudios Mexicanos y Centroamericanos, México, D.F.

Barnes, N. y K. Reilly 2007. Conceptuación de las redes transnacionales: una revisión de literatura selecta. En Redes Transnacionales en la Cuenca de los Huracanes. Un Aporte a los Estudios Interamericanos, coordinado por F. Pisani, N. Saltalamacchia, A.B. Tickner y N. Barnes, pp. 63-92. M.A. Porrúa librero-editor, Instituto Tecnológico Autónomo de México, H. Cámara de Diputados LX Legislatura, México, D.F.

Bartra, R. 2001. Cultura y Melancolía. Anagrama, Barcelona.

Besserer, F. 2016. Intersecciones Urbanas: Ciudad Transnacional/ Ciudad Global. Colección Estudios Transnacionales. Ed. Universidad Autónoma Metropolitana y Juan Pablo Editor, México, D.F.

Boas, F. 1964. Cuestiones Fundamentales de Antropología Cultural. Ediciones Solar, Buenos Aires.

Bonnett, A. 2016. The Geography of Nostalgia: Global and Local Perspectives on Modernity and Loss. Routledge, Londres.

Boym, S. 2016. El Futuro de la Nostalgia. Editorial Antonio Machado, Madrid.

Cárdenas, R. 2004. La Papa, patrimonio de la humanidad. El Llanquihue de Puerto Montt, diario local 1-4.

Cárdenas, R. y C. Trujillo 1986. Caguach, la Isla de la Devoción. Religiosidad Popular en Chiloé. Ediciones LAR, Santiago.

Collier, S y A. Ong 2005 Global Assemblages. Blackwell, Malden.
Danemann, M. 1974. Teoría folklórica. Planteamientos críticos y proposiciones básicas. En Teorías del Folklore en América Latina. Instituto Iberoamericano de Etnología y Folklore del Centro Multinacional del Programa Regional de Desarrollo Cultural de la OEA, Caracas.

Damasio, A. 2002. Le Sentiment Même de Soi, Corps, Émotions, Conscience. Éditions Odile Jacob, París.

Falzon, M.A. 2009. Multi-Sited Ethnography. Theory, Praxis and Locality in Contemporary Research. Ashgate Publishing, Farnham.

Ferrando, M. 2004. Al Otro Lado del Pacífico: Japoneses en Chile 1900-1960. Ograma, Santiago.

Freud, S. 1974. Duelo y Melancolía. Biblioteca Nueva, Madrid.

Gallo, E. 2009. In the right place at the right time? Reflections on multi-sited ethnography in the age of migration. En Multi-Sited Ethnography. Theory, Praxis and Locality in Contemporary Research, coordinado por M.A. Falzon, pp. 87-102. Ashgate Publishing, Farnham.

Garcés, A. 2015. Migración Peruana en Santiago. Prácticas, Espacios y Economías. Ril Editores, Santiago.

Garcés, A, J. Moraga y M. Maureira 2016. Tres movilidades para una ruta. Espacio, comercio y transnacionalidad boliviana en Tarapacá. Estudios Atacameños 53:205-220.

Geertz, C. 1987. La Interpretación de las Culturas. Gedisa, México, D.F.

Glick-Schiller, N. 2008. Nuevas y Viejas cuestiones sobre localidad: teorizar la migración transnacional en un mundo neoliberal. En Nuevos Retos del Transnacionalismo en el Estudio de las Migraciones, coordinado por C. Solé, S. Parella y L. Cavalcanti, pp. 21-46. Ministerio de Trabajo e Inmigración-Grafo S.A, Madrid.

Goldring, L. y P. Landolt 2009. Reformulación de las unidades, identidades, temporalidades, cultura y contextos: reflexiones sobre la investigación de los movimientos migratorios. En Encuentros Disciplinarios y Debates Metodológicos: La Práctica de la Investigación sobre migraciones y movilidades, editado por L. Rivera y F. Lozano, pp. 125-161. Miguel Ángel Porrúa-Crim-Unam, México, D.F. 
González, S. 2009. El Norte Grande de Chile y sus dos triples fronteras: Andina (Perú, Bolivia y Chile) y Circumpuneña (Bolivia, Argentina y Chile). Cuadernos Interculturales 7 (13):27-42.

González Calvo, V. 2005. El duelo migratorio. Trabajo Social 7:77-97.

Gonzales y Gonzales, L. 1986. Invitación a la Microhistoria. Fondo de Cultura Económica, México, D.F.

Guarnizo, L. 2003. The economics of transnational living. International Migration Review 37 (3):666-699.

Guizardi, M. y A. Garcés 2013. Circuitos migrantes. Itinerarios y formación de redes migratorias entre Perú, Bolivia, Chile y Argentina en el norte grande chileno. Papeles de Población 78:65-110.

Guizardi, M., F. Valdebenito, E. Nazal y E. López 2017. Hyperborder spaces: Peruvian migrants in the Arica Bus Terminal (Chile). Migraciones Internacionales 9 (1):152-178.

Hannerz, U. 1992. Escenarios para las culturas periféricas. Alteridades 2 (3):94-106.

Hannerz, U. 1996. Transnational Connections. Routledge, LondonNew York.

Hirai, S. 2012. ¡Sigue los símbolos del terruño!: etnografía multilocal y migración transnacional. En Métodos Cualitativos y su Aplicación Empírica: por los Caminos de la Investigación sobre Migración Internacional, coordinado por M. Ariza y L. Velasco, pp. 81-115. UNAM-El Colegio de la Frontera Norte, A.C, México, D.F.

Instituto Nacional de Estadística de Chile 2012. Resultados preliminares Censo de Población y Vivienda. Instituto Nacional de Estadísticas, Santiago. Recuperado de: www.ine.cl

Kearney, M. 2003. Fronteras y límites del Estado y el YO al final del imperio. Alteridades 13 (25):47-52.

Khagram, S. y P. Levitt 2008. Contructing transnational studies. En The Transnational Studies Reader, coordinado por K. Sanjeev y P. Levitt, pp. 273-274. Routledge, Nueva York.

Knauer, L. 2003. Remesas multidireccionales y etnografía viajera. Sociedade e Cultura 6 (1):13-24.

Levitt, P. 1998. Social remittances: A local-level, migration driven form of cultural diffusion. International Migration Review 32 (4):929-949.

Levitt, P. y N. Glick-Schiller 2004. Conceptualizing Simultaneity: A Transnational Social Field Perspective on Society. En The Transnational Studies Reader, coordinado por K. Sanjeev y P. Levitt, pp. 284-298. Routledge, Nueva York.

Marcus, G. 1995. Etnografía en/del sistema mundo. El surgimiento de la etnografía multilocal. Alteridades 11 (22):111-127.

Mancilla, L. y L. Mardones 2010. El Terremoto de 1960 en Castro. Ediciones La Tijera, Castro.

Manns, P. 1972. Los Terremotos Chilenos. Editorial Quimantú, Santiago.

Martinic, M. y D. Campbell 2010. Las comisarias rurales del antiguo territorio de colonización de Magallanes (1902-1927). Magallania 38 (19):205-226.

Montiel, F. 2010. Chiloé. Historias de Viajeros. Municipalidad de Castro, Castro.

Pandolfi, L. 2016. Caleuche, Mitología de una Incomprensión. Gente Transformada, Gente que se Transforma, Representaciones Identitarias de los Williche de Chile. Abya-Yala, Quito.

Pedone, C. y S. Gil 2008. Maternidades transnacionales entre América Latina y el Estado español. El impacto de las políticas migratorias en las estrategias de reagrupación familiar. En The Transnational Studies Reader, coordinado por K. Sanjeev y P. Levitt, pp. 149-176. Routledge, Nueva York.

Pries, L. 2008. Transnational societal spaces. Which units of analisys, references and measurement. En Rethinking Transnationalims. The Meso-Link of Organization, editado por Ludger, P, pp. 1-20. Routledge Editor, Londres.

Saavedra Gallo, G. 2015. Los futuros imaginados de la pesca artesanal y la expansión de la salmonicultura en el sur austral de Chile. Chungara Revista de Antropología Chilena 47 (3):521-538.

Saldivar, J. 2015. Viviendo la religión desde la migración, transnacionalización de la santería cubana en Lima, Perú, La Paz, Bolivia y Santiago, Chile (1980-2013). Reflexiones 94 (2):133-144.

Saldivar, J. 2016. ¡Oh mío Yemayá! difusión masificación y transnacionalización de la santería cubana en Bolivia. Revista Brasileira do Caribe 17 (33):135-159.

Saliéres, M., M. Le Grix, V. Matthieu, W. Vera y R. Billaz 2005. La agricultura familiar chilota en perspectiva. Revista Líder 13 (10):79-104.

Sassone, S. 2002. Espacios de vida y espacios vividos. El caso de los inmigrantes bolivianos en el área metropolitana de Buenos Aires. El Éxodo Andino. La Migración Transnacional desde Bolivia, Ecuador y Perú, editado por T. Salman y A. Zoomers, pp. 91-121. Cuadernos del CEDLA, Amsterdam.

Silva, C. 2011. Campamentos urbanos en un país de centros y periferias: expresión de una pobreza sistémica. Revista Urbano 23:7-19.

Sinatti, G. 2008. Migraciones, transnacionalismo y locus de investigación: multi-localidad y la transición de "sitios" a "campos". En Nuevos Retos del Transnacionalismo en el Estudio de las Migraciones, coordinado por C. Solé, S. Parella y L. Cavalcanti, pp. 91-112. Ministerio de Trabajo e InmigraciónGrafo S.A, Madrid.

Stefoni, C. 2004. Inmigrantes transnacionales: la formación de comunidades y la transformación en ciudadanos. En FLACSO, Santiago. Consultado el 23/02/2011 disponible en: http://bibliotecavirtual.clacso.org.ar/ar/libros/chile/flacso/ artstef.pdf

Steigenga, T., I. Palma y C. Girón 2008. El transnacionalismo y la movilización colectiva de la comunidad maya en Júpiter, Florida. Ambigüedades en la identidad transnacional y religión vivida. Migraciones Internacionales [online] 4 (4):37-71. Consultado el 10 de julio de 2016. Disponible en: http://www. scielo.org.mx/scielo.php

Soja, E. 1997. El tercer espacio. Ampliando el horizonte de la imaginación geográfica. Geográfikos 8:71-76.

Soja, E. 2008. Postmetrópolis. Estudios Críticos sobre las Ciudades y las Regiones. Traficantes de Sueños, Madrid.

Ther Ríos, F. 2011. Configuraciones del Tiempo en el Mar Interior de Chiloé y su relación con la apropiación de los Territorios Marítimos. Desenvolvimento e Meio Ambiente 23:67-80.

Urbina, R. 2002. La Vida en Chiloé en Tiempos del Fogón 19001940. Universidad Playa Ancha Editorial, Valparaíso.

Valdebenito, F. 2017. La producción espacial de la frontera norte chilena (1885-1930): un debate inconcluso. Límite 12 (38):39-49.

Vázquez de Acuña, I. 1993. La jurisdicción de Chiloé (siglos XVI al $\mathrm{XX)}$. Su extensión, exploración y dominio. Boletín de la Academia Chilena de la Historia 103:111-191. 
Viladrich, A. y D. Cook 2008. Discursos transnacionales de inclusión étnica: El caso de los "Españoles por adopción". En Nuevos Retos del Transnacionalismo en el Estudio de las Migraciones, coordinado por C. Solé, S. Parella y L. Cavalcanti, pp. 117-200. Ministerio de Trabajo e InmigraciónGrafo S.A., Madrid.

\section{Notas}

${ }^{1}$ Este trabajo muestra avances del proyecto FONDECYT 3160798 "Etnografías en movimiento: imaginarios culturales y trayectorias migratorias de comunidades transnacionales chilotas entre Ushuaia (Argentina y Punta Arenas (Chile) 19502015".

${ }^{2}$ La descomposición del vocablo alude al griego "algia", como la necesidad del "nostos", retorno a un nosotros mismo. Si bien es cierto que utilizamos la noción como un sentimiento para demostrar la necesidad del regreso que incluye también los imaginarios del terruño (tiempo dejado atrás), en un principio se empleo para referirse a dolencias corpóreas.

${ }^{3}$ Entendemos el ensamblaje como la unión de elementos que, aunque diversos, logran concentrarse y habituarse en espacios disímiles de significado. En antropología transnacional, Ong (2012) reconoce la conveniencia de este concepto para referirse a las conexiones políticas y económicas que se desarrollan entre países a través de la migración y circulación de recursos. Si bien es cierto que la noción de ensamblaje global (Collier y Ong 2005), afirma dichas continuidades, también nos permite reflexionar sobre conexiones culturales en la migración vivida sucedidas a través de hallazgos históricos en territorios translocales.

${ }^{4}$ La propuesta de macrozona sur patagónica pretende contribuir a los estudios sobre migración transnacional abordados en el Norte Grande, singularizando espacios de movilidad y conexiones entre límites fronterizos norte-norte y sur-sur de Chile. En particular, nos interesa localizar puntos de encuentro en las dinámicas migratorias que se generan entre bordes geográficos, así como también, conocer ensamblajes de nuevos migrantes modelados por lugares de acogida, sus contribuciones y relaciones entre sus lugares de origen y residencia transnacional.

${ }^{5}$ Utilizamos la definición estricta de la categoría migrantes sobre otras como inmigrantes o emigrantes, para no tropezar con la perspectiva transnacional. En todo caso, la propuesta de transmigrantes podría ser de utilidad para repensar este tipo de movilidades transnacionales (Pries 2008).

${ }^{6}$ Macro zoom etnográfico. Unidad de análisis que permite localizar personas, lugares y espacios de hipermovilidad. Se representa como un continuum de prácticas culturales y conexiones en diferentes etapas históricas.

${ }^{7}$ La etnografía es una descripción densa en medida que se convierte en "una multiplicidad de estructuras conceptuales complejas [...] superpuestas o entrelazadas entre sí, estructuras que son al mismo tiempo extrañas, irregulares, no explícitas, y a las cuales el etnógrafo debe ingeniarse de alguna manera, para captarlas primero y para explicarlas después" (Geertz 1987:24).

${ }^{8}$ Sugerimos la noción particularista del concepto cultura como "totalidad de las reacciones y actividades mentales y físicas que caracterizan la conducta de los individuos componentes de un grupo social, colectiva e individualmente, en relación a su ambiente natural, a otros grupos, a miembros del mismo grupo y de cada individuo hacia sí mismo" (Boas 1964:166). Sin embargo, también creemos en el giro epistemológico a través de su posición simbólica de la etnología fenomenológica donde "la cultura consiste en estructuras de significación socialmente establecidas en virtud de las cuales la gente hace cosas" (Geertz 1987:26). En este sentido, el "incremento en el tráfico cultural y de la transferencia a gran escala de los sistemas de significado y las formas simbólicas, el mundo se está convirtiendo cada vez más en una unidad [...] en términos de su construcción cultural" (Hannerz 1992:94). Por tanto, una definición adecuada para el entramado simbólico de la cultura sería "el conjunto de los procesos sociales de significación [...] producción, circulación y consumo de la significación en la vida social" (García Canclini 2004:34).

${ }^{9}$ Es relevante sostener que la masiva migración de chilotes hacia lugares del sur austral provocó una joroba migratoria, sin embargo, el retorno más allá de exitoso en sentido de personas que regresaron a sus lugares de origen, también pude comprenderse como ambivalente debido al grueso calibre que decidió asentarse en lugares como Río Gallegos, Río Turbio, Río Grande, Ushuaia, Comodoro Rivadavia, etc. Estas migraciones se integraron de manera definitiva a sus lugares de residencia, quienes también siguieron custodiando las tradiciones culturales visibilizadas en actividades, prácticas, objetos e instituciones que legitiman a los chilotes en los espacios de ensamblaje.

${ }^{10}$ Las ceremonias de velación de muertos es una práctica cultural donde interactúan aspectos de conexión y transición, por ejemplo los ritos nahuas de velación en México o la ceremonia del ituto (refrescar el cuerpo para su camino hacia otonowá) entre practicantes de santería-Ifá cubanas. En Chiloé, la particularidad en la tradición se visibiliza en la performatividad con marcadas diferencias en áreas rurales y urbanas. En la primera se observan aspectos tradicionales como el tiempo de velación, dos o tres días, se convocan a los fiscales y rezadoras quienes ejecutan las ceremonias en rezos y cánticos. Se invita a los presentes "mucha comida y bebida", son ellos quienes ofrecen o "pasan plata" a las rezadoras para continuar con las ceremonias, entre 6 u 8 horas seguidas. En ocasiones se contratan "lloronas". El cortejo fúnebre es acompañado con música, acordeón, guitarra y otros instrumentos. En áreas urbanas los fallecidos son transportados al velatorio, se convocan a los familiares y amigos quienes son acompañados por el sacerdote y monjas quienes ofician las ceremonias hasta el cementerio.

${ }^{11}$ Para una mayor comprensión sobre la afectividad desde las neurociencias, ver Damasio 2002.

${ }^{12}$ Retomamos la idea de flux capacitor como metáfora que nos ayuda a reflexionar en algunas características de reconfiguración migratoria desde una perspectiva transnacional, como la música, la nostalgia, la matria, el terruño, los espacios vividos, etc. Es entonces la capacidad e inmediatez de la memoria histórica, aquella que se nutre de las experiencias y cotidianidades de la vida social, conexiones con el pasado desde el presente.

${ }^{13}$ Desplazamientos territoriales espacio temporales de comunidades hacia lugares multiescalares donde individuos experimentan emociones afectivas e identitarias provocadas por las lejanías del terruño. Particularmente nos referirnos a los cruces de fronteras y nuevos ensamblajes de personas en lugares de residencia (hábitat simbólicos), legitimados a través de la formación de comunidades, circulación de objetos, extensión de mercados y visibilización de tradiciones culturales (musicales, religiosas, comunitarias).

${ }^{14}$ Conexiones históricas entre comunidades que comparten espacios territoriales, culturales, económicos y políticos mediante la construcción de una memoria colectiva de ancestralidades e identidades en movimiento. 